\title{
MILITARIZACIÓN VISUAL EN MOMENTOS DE CRISIS: LOS CASOS DE LENIN MORENO Y SEBASTIÁN PIÑERA DURANTE LAS MOVILIZACIONES DE OCTUBRE DE 2019
}

\author{
VISUAL MILITARIZATION DURING CRISIS: THE LENIN \\ MORENO AND SEBASTIÁN PIÑERA'S CASES DURING \\ THE PROTESTS OF OCTOBER 2019
}

\section{Francisco Javier Verdes-Montenegro Escánez ${ }^{1}$}

ORCID: 0000-0002-3521-0273

\section{RESUMEN}

Ante el renovado protagonismo adquirido por el factor militar en América Latina, y en especial el rol que han tenido los cuerpos castrenses en distintas crisis que han sacudido la región a lo largo de 2019, desde Venezuela a Bolivia, pasando por Ecuador o Chile, este trabajo profundiza en lo que se define como un proceso de "remilitarización" en la región. Concretamente, se ahonda en uno los rasgos singulares que está teniendo el nuevo protagonismo de las Fuerzas Armadas en América Latina: su uso con un componente visual en situaciones de crisis políticas y cuestionamiento de los mandatarios. Por ello, en primer lugar, se revisará y sintetizará el estado de los debates teórico-metodológicos en las relaciones internacionales para analizar este componente visual. Posteriormente, se expondrá como marco histórico la dinámica de remilitarización en la que se inscribe el análisis en América Latina, señalando sus principales rasgos y efectos en la región. Y para acabar, se completará con un análisis de discurso visual y verbal de carácter cualitativo que prestará atención al rol que han cumplido las Fuerzas Armadas latinoamericanas en dos crisis políticas que han irrumpido durante el mes de octubre de 2019 en la región: Ecuador y
Chile. Como se verá, en ambos casos se proyecta visualmente un doble mensaje: por un lado, el apoyo de las Fuerzas Armadas en un momento de cuestionamiento del liderazgo y la gestión del mandatario en cuestión; y por otro, la pretensión de disuadir a quienes secunden las protestas que originan las alocuciones.

Palabras clave: Chile; Ecuador; Fuerzas Armadas; discurso; militarización; militarización visual

\section{ABSTRACT}

Faced with the renewed prominence acquired by the military factor in Latin America and in particular the role that castrenses have played in various crises that have shaken the region throughout 2019, from Venezuela to Bolivia, through Ecuador or Chile, this work delves into what is defined as a process of "remilitarization" in the region. Specifically, it delves into a new feature int the armed forces in Latin America: being used with a visual component in situations of political crisis or when the policy-makers power is questioned. Therefore, first, the work deeps on the theoretical-methodological discussions in International Relations to

1 Universidad Complutense de Madrid, España. Investigador del Instituto Complutense de Estudios Internacionales (ICEI-UCM). Doctor en Ciencias Políticas y Relaciones Internacionales. Correo electrónico: fjverdes-montenegro@ucm.es 
analyze this visual component. Subsequently, the dynamic of remilitarization that emerged in Latin America will be presented from a historical perspective, pointing out its main features as well as the effects in the region. And in the end, it will be completed with a visual and verbal discourse analysis of qualitative character that will pay attention to the role played by the Latin American armed forces in two political crises that have erupted during October 2019 in the region: Ecuador and Chile. Then, a double message is projected visually: on one hand, the support of the Armed Forces when the president's leadership is questioned; and on the other side, the attempt to dissuade those who support protests.

Keywords: Chile; Ecuador; armed forces; discourse; militarization; visual militarization

\section{Introducción}

A raíz de las movilizaciones que tuvieron lugar en Ecuador, con motivo de un decreto presidencial que eliminaba los subsidios a los combustibles, y con una marcha hacia la capital ecuatoriana ya convocada por distintos movimientos indígenas, el presidente Lenin Moreno anunció, en una rueda de prensa, la adopción del estado de excepción y el traslado provisional del gobierno a Guayaquil. Dicha alocución no se produjo en solitario, ya que el mandatario apareció respaldado por cuatro altos mandos militares. Preguntado al respecto, el propio canciller ecuatoriano, José Valencia, afirmó que "la presencia de los militares durante la comparecencia del presidente es una forma de ratificar visualmente el respaldo de las Fuerzas Armadas al Gobierno" (España, 2019). Pocos días después, la imagen de un presidente secundado por las Fuerzas Armadas se repetía, esta vez en Chile, tras unas protestas provocadas inicialmente por el aumento de la tarifa del transporte público, y en las que el Gobierno de Piñera tuvo que afrontar la mayor crisis política desde que asumiera su segundo mandato, con un despliegue de militares en las calles nunca visto desde el fin de la dictadura militar.

Estas dos imágenes no han sido fenómenos aislados en América Latina en los últimos años, y en otros países como Bolivia, Brasil, El Salvador, Guatemala o Venezuela se han registrado instantáneas en las que las Fuerzas Armadas acompañan a los mandatarios de los respectivos países durante crisis políticas provocadas por conflictos colectivos internos. Ahora bien, en todas ellas se observa cómo las Fuerzas Armadas de dichos países, cuerpos institucionalizados para defender el país de amenazas externas e instrumentos de Estado para situaciones excepcionales, son empleadas para fines que no se corresponden del todo con el mandato democrático que se les ha asignado y el deber de neutralidad política correspondiente. Tras la ola de dictaduras militares que tomaron por asalto a varios países latinoamericanos en la segunda mitad del siglo XX, este renovado protagonismo por parte de los cuerpos castrenses se constata en distintas situaciones críticas en los que estos son instrumentalizados por parte de los mandatarios, y con un fuerte componente visual sobre el que conviene detenerse y reflexionar. 
En ese sentido, ante este renovado protagonismo de las Fuerzas Armadas en la región durante la gestión de crisis políticas, el presente trabajo profundiza en una de las caras de lo que se ha definido en otras investigaciones como "nuevo militarismo" (Diamint, 2015) o un proceso de "remilitarización" en América Latina (Scharpf, 2020; Verdes-Montenegro, 2019), concretamente, en uno de los rasgos singulares que está teniendo esta dinámica respecto a lo sucedido durante las dictaduras militares del siglo XX. Como se expondrá, la hipótesis que se maneja es que la militarización en ciernes ya no se caracteriza por la "toma del palacio" presidencial mediante el uso de la fuerza, sino que esta opera por invitación de los propios mandatarios, quienes se proyectan al lado de las Fuerzas Armadas en situaciones de crisis con un doble propósito: por un lado, visibilizar y reforzar, en momentos de cuestionamiento de sus decisiones, a quien detenta la soberanía; y por otro, disuadir a los actores políticos que pretenden pugnar o manifestar su disenso.

De este modo, el trabajo se inscribe desde un prisma teórico en la incipiente bibliografía sobre política visual aplicada a las relaciones internacionales, dentro de los denominados estudios de seguridad visual -VSS, por sus siglas en inglés- (Vuori y Andersen, 2018), y la Visual Global Politics (Bleiker, 2015). Se atienden, así, los efectos performativos que generan las imágenes; es decir, cómo estas últimas y las subjetividades políticas se articulan para intentar legitimar un abanico de respuestas políticas (Adler-Nissen et al., 2020). Como plantea Roland Bleiker (2015), para un análisis de la política visual global, se adoptará una metodología pluralista que, en este caso, se materializa en un análisis de discurso visual y verbal, a partir de fuentes primarias (imágenes difundidas y discursos retransmitidos, respectivamente), y completado con fuentes secundarias vinculadas con esos acontecimientos (artículos de prensa y especializados).

Por ello, en primer lugar, se atenderá con más precisión el marco teórico-metodológico empleado para analizar este componente visual, y que en las relaciones internacionales se ha denominado como el giro "pictórico". Posteriormente, se expondrá como marco histórico la dinámica de remilitarización en la que se inscribe el análisis y que ha emergido en América Latina, señalando sus principales rasgos y efectos en la región. En tercer y último lugar, se completará con un análisis de discurso visual y verbal de carácter cualitativo que prestará atención al rol que han cumplido las Fuerzas Armadas latinoamericanas en dos crisis políticas que irrumpieron durante el mes de octubre de 2019 en la región: Ecuador y Chile. En ambos casos, tras dos decisiones gubernamentales que generaron descontento en amplios sectores de la población y con un elemento visual compartido: una rueda de prensa del presidente en un momento clave de la crisis política secundado por las Fuerzas Armadas. 


\section{El giro "pictórico" en las Relaciones Interna- cionales y la agenda de securitización visual}

Las imágenes juegan un rol cada vez más importante en la política global, al punto de que en la academia hablan de giro "pictórico" o "visual" (Mitchell, 1994) e, incluso, de una "era de la imagen" (Williams, 2018). Desde la disciplina de las relaciones internacionales, los primeros análisis llevados a cabo en los ochenta y noventa en los que se problematiza en torno al factor visual fueron desarrollados por parte de grupos académicos integrados en corrientes posestructuralistas y críticas, como los trabajos de David Campbell, James Der Derian, Michael J. Shapiro, Jutta Weldes (Schlag, 2019).

Como señalaba una de las mayores exponentes dentro de la disciplina, Lene Hansen, las imágenes funcionan diferente a las palabras, dado que son no-verbales en sí mismas, por lo que aprehender su análisis y estudio requiere atribuirles palabras que le otorguen significado político (Hansen, 2011). Hay algo único en las imágenes, ya que evocan, apelan a algo o alguien, y generan emociones, si bien estas últimas son difíciles de determinar. Esa interpretación de las imágenes, puesto que no tienen ningún significado intrínseco, es contingente al contexto verbal en el que está incrustada. Por ello, existe siempre un "salto de sentido" (leap of meaning) que fuerza a quien investiga a ofrecer una interpretación particular. Es decir, en lugar de esconder la elección adoptada, debe poner al descubierto el camino adoptado y las renuncias, con una imprescindible labor de reflexividad durante el propio proceso de investigación.

Estos retos epistemológicos, además, se han exacerbado con la rapidez y complejidad que circulan las imágenes. Tendencia que algunos estudios denominan como "democratización", ya que hoy en día se ha facilitado la capacidad de hacer una foto y distribuirla vía red social (Facebook, Twitter, Instagram, TikTok, etc.) con un impacto más allá de las fronteras nacionales. Por lo tanto, la manera de afrontar el modo a través del cual las imágenes se "hacen", y cómo las usamos/analizamos, ha sido un terreno "resbaladizo" y "peligroso" que ha generado gran preocupación en las relaciones internacionales, máxime por la preponderancia de algunas metodologías más ortodoxas que ignoran estas cuestiones (Cooper-Cunningham, 2020; Moore y Farrands, 2013). Así, surge la interrogante sobre ¿cómo abordar el análisis de un objeto de estudio ambiguo, polémico, fluido y no verbal?

Ante un debate en términos metodológicos que está abierto, teóricos como Roland Bleiker (2014) han resuelto con una llamada a un pluralismo metodológico y la apuesta por una aproximación teórica alineada con la teoría de montaje 
(assemblage theory) y el concepto de "rizoma" (rhizomes) que popularizaron Deleuze y Guattari (1987). En definitiva, como reconoce el propio autor de la compilación Visual Global Politics (2018), su controvertida y necesaria propuesta es una combinación heterogénea de aparentes métodos incompatibles para comprender la compleja relación entre imágenes y política, rompiendo con profundas convenciones incrustadas en las ciencias sociales (Bleiker, 2015).

En ese sentido, el significado de las imágenes depende siempre del contexto y la interpretación, y su impacto es más difuso y no responde a lógicas de causalidad. Tampoco hay ningún método concreto para comprender lo que las imágenes son y cómo operan. Existen distintos aspectos que entran en juego, como aspectos técnicos/tecnológicos, composicionales o sociales. Así, hay como mínimo tres dimensiones vinculadas a lo visual, (i) la construcción de la imagen, es decir, el proceso a través del cual se produce, selecciona y difunde; (ii) el contenido de la imagen en sí misma, y cómo interactúa con otro medios y objetivos; y (iii) el impacto o cómo se recibe la imagen por cada una de las audiencias a las que llega. Por supuesto, cada una de estas dimensiones requiere unos métodos y capacidades en el uso de metodologías dispares.

Entre los diversos métodos empleados, en este caso merece especial mención el análisis de discurso. Como apunta una referente en metodologías visuales en ciencias sociales como Gillian Rose, este método se preocupa por el lenguaje, aunque también en el modo a través del cual las imágenes construyen visiones específicas. Por ello, presta especial atención a la imagen en sí misma, a su producción social y efectos. Otro aspecto por destacar es que a través de este método se puede analizar, al mismo tiempo, un discurso tanto en su componente visual como verbal (Rose, 2016).

Respecto a su desarrollo en los estudios sobre seguridad en las relaciones internacionales, en línea con Roland Bleiker, Andersen y Vuori (2018) abogan por la necesidad de una aproximación flexible y abierta al análisis de lo visual desde esta área. Con ello, lo que denominan como el "nexo visualidad-seguridad" (visuality-security nexus) ha cobrado especial interés y protagonismo. Como señalan estos mismos académicos, ¿es posible pensar un conflicto o cuestión de seguridad en la que la visualidad no sea importante? Desde la Guerra de Vietnam, pasando por los dos conflictos en Irak, sin perder de vista Afganistán o Siria, todos ellos cuentan con un elemento visual clave impregnado en los imaginarios y del que subyace un componente político intrínseco.

Ahora bien, los vínculos entre seguridad y lo visual son diversos, aunque muchos de ellos han gravitado en torno a la teoría de la securitización en los últimos años. Esta vinculación con la teoría desarrollada por la Escuela de 
Copenhague, y revisada desde hace dos décadas, permite adoptar una aproximación discursiva, y abrir el abanico de preguntas en torno a lo "securitario". Es decir, permite que afloren una serie de preguntas como: quién securitiza, cómo se construye una cuestión como un asunto de seguridad, cómo, con qué propósitos y qué resultados. Gracias a esta propuesta teórica que se articula en torno a la securitización, la agenda visual irrumpe enriqueciendo a la primera y completando su propuesta con la agenda de securitización visual (Verdes-Montenegro, 2015).

Entre los distintos trabajos que han abordado la agenda de securitización visual, pueden destacarse las aportaciones de Juha Vuori (2010 y 2013) en las que, gracias a las interrelaciones con la semiótica de Pierce, profundiza en torno a los artefactos visuales y qué rol cumplen a la hora de securitizar y desecuritizar. Por su parte, Lene Hansen (2011 y 2014) y Heck y Schlag (2013) se aproximan al análisis de la visualidad-securitización a partir de la iconología. Lene Hansen (2018) establece distintas formas de integrar las imágenes en el proceso político de definir la seguridad: como prueba, como representación de la amenaza o como comunicación emocional (miedo, compasión, cuidado, lástima, etc.).

A diferencia de esta, Heck y Schlag (2013) parten de una aproximación que no subestima lo icónico en sí mismo y aborda la performatividad que tiene una imagen - por lo que denota y representa - desde los planteamientos que desarrolla Bredekemp con su concepto de "auto-actividad". Entendiendo esto último como la forma en la que lo visual habla con un sentido metafórico, y más allá de la imagen exclusivamente, amplía lo visual a relaciones constitutivas sobre el "viendo/mostrando" (seeing/showing), y sus ausencias. Metodológicamente, la iconología también aporta una aproximación en tres etapas, a partir de los trabajos que desde la historia del arte fueron impulsados por Erwin Panofsky: (i) descripción pre-icónica (experiencias prácticas en aras de descodificar los sujetos y objetos expuestos), análisis iconográfico (comprender lo visual en su sentido convencional y alegórico), y (iii) interpretación iconográfica (describiendo tipos y estilos, su forma simbólica en el contexto histórico, político y social).

De acuerdo con esta comprensión de lo visual, y recurriendo a un análisis de discurso que tenga en cuenta las tres etapas apuntadas por Heck y Schlag, y en el que se combina la importancia otorgada a lo visual con lo discursivo, se analizarán los dos casos de estudio en cuestión, sin perder de vista las ausencias. Antes, y a continuación, se precederá a una contextualización de la dinámica de remilitarización en la región, atendiendo a sus causas. 


\section{El proceso de remilitarización en América Latina: Proliferación de roles y más prerrogativas}

Tras la caída del Muro de Berlín, los gobiernos latinoamericanos tuvieron que dar continuidad al formidable desafío de democratizar, desideologizar y situar en marcos civiles las visiones y doctrinas de seguridad y defensa dominantes durante el periodo de la Guerra Fría. Pese a esa amplia tendencia que se abre paso ya en los ochenta, las particulares correlaciones de fuerza de cada país respecto a la democratización de las Fuerzas Armadas, la redefinición de las relaciones cívico-militares y los condicionantes geopolíticos marcaron, en cada uno de los países, los ritmos y el contenido del proceso. La instauración de regímenes democráticos no derivó automáticamente en garantías de gobernabilidad y estabilidad (Hens y Sanahuja, 1995; Martínez y Rubio, 2017).

En este debate, se entremezclaron la discusión sobre las nuevas visiones de seguridad ampliadas (seguridad cooperativa, seguridad democrática, etc.), las opciones de política exterior - en particular las relaciones con Estados Unidos-, el rol y la autonomía del estamento castrense en el nuevo contexto democrático y los propios recursos que debían destinarse (Diamint, 2001). Los cambios en las funciones, recursos y papel de las Fuerzas Armadas son un debate clave en este periodo, lo cual se ha ido retomando posteriormente en algunos países. El fin de la lógica bipolar y los procesos de democratización supusieron una "crisis de misión" para las Fuerzas Armadas, de la que se trató de salir con una combinación de funciones viejas y nuevas, como la tradicional defensa territorial, la respuesta a los desastres o las misiones internacionales en las que empezaron a participar con más ahínco los países del Cono Sur, en especial, Argentina, Brasil, Chile y Uruguay (Sanahuja y Verdes-Montenegro, 2014).

La tendencia de remilitarización que se está apreciando en la coyuntura actual en varios países de la región descansa nuevamente en distintos factores explicativos. En buena medida, todos ellos tienen como trasfondo la crisis de identidad (o de misión) que experimentan las Fuerzas Armadas, y la redefinición de su papel más allá de la labor tradicional que se les ha atribuido en sistemas democráticos. Es decir, la respuesta a las denominadas "viejas amenazas", con la preparación, vigilancia y defensa de la soberanía y el territorio de un Estado concreto, con una organización jerarquizada en la que imperan valores como la disciplina o la abnegación, y en cuyo margen de acción se prevé el uso de la fuerza, estrictamente como defensa ante un ataque externo. Así, las nuevas funciones que se han identificado en otros trabajos son, en varios casos, factores que han sentado las bases de la dinámica de remilitarización apreciada. 
Por ello, a continuación, se señalan cuatro de estos factores explicativos, acompañados de las nuevas funciones a las que se les ha asociado: (i) las limitaciones de las transiciones a la democracia y, junto con ellas, las prerrogativas que se mantienen; (ii) el desborde a la hora de afrontar las amenazas transnacionales; (iii) reaseguro frente a crisis políticas y sociales, mediante cooptación e influencia, y (iv) la desafección hacia la política y los políticos a raíz de la corupción. Por ello, la militarización que se está constatando en América Latina está teniendo ya una serie de consecuencias que empiezan a hacerse patentes: (i) decisiones que siguen escapando al poder civil, (ii) discursos maniqueos y virulentos, (iii) políticas de "mano dura" y (iv) privilegios y fueros (VerdesMontenegro, 2019).

Se aprecia así una proliferación de responsabilidades asignadas a las Fuerzas Armadas - o asumidas por estas - : desde la de lobby empresarial, pasando por la asunción de labores policiales, a raíz de las políticas de "mano dura", hasta su carácter de "guardianes de la patria" ante crisis políticas y sociales. Ahora bien, el caso de Bolsonaro en Brasil está mostrando un nuevo papel que añade más complejidad a la dinámica de remilitarización: el de fungir como cuadros políticos de carácter tecnocrático, legitimados mediante procesos electorales, y a los que se asocia con rasgos de efectividad y menos propensión a la corrupción. Este componente de "honestismo" atribuido a las Fuerzas Armadas también se está observando en algunas medidas implementadas en México durante el mandato de López-Obrador. Este aspecto que se ha denominado en otros trabajos como "khakiwashing" representa un rasgo novedoso de esta dinámica de remilitarización (Verdes-Montenegro, 2019).

Por ello, el espacio político que están ganando las Fuerzas Armadas en distintos países de América Latina refleja una dinámica de remilitarización en la región que merece reflexionar profundamente desde un prisma democrático, tanto por las repercusiones que ya está teniendo como por las que puede tener a corto y medio plazo.

\section{Cegados ante los efectos visuales: Proyección de soberanía y disuasión}

Las movilizaciones políticas que se sucedieron en el último trimestre de 2019 en Ecuador, Chile, Colombia o Bolivia recuperaron el foco de atención hacia América Latina y pusieron en jaque a los mandatarios de los respectivos países con algunas de las crisis políticas más graves que se han registrado en los últimos años (E. Rodríguez, 2020). En todas ellas hubo un actor que entró en juego como elemento común: las Fuerzas Armadas a través de una serie de acciones, 
tanto de despliegue en las calles como con imágenes que no son fruto del azar. Si bien los motivos directos que justificaron esas protestas no son iguales, sí comparten unos elementos comunes de frustración y desencanto de amplios sectores de la población, en un contexto estructural de crisis de globalización (Sanahuja, 2018) con elementos sociopolíticos de fondo, como el "malestar" o "fatiga" hacia la democracia, y el menor dinamismo económico, con una desigualdad creciente y un aumento de la pobreza (Sanahuja, 2019).

En este trabajo, como se ha adelantado, se va a abordar el caso de las dos crisis políticas registradas en Ecuador y Chile durante el mes de octubre de 2019, en ambos casos tras dos decisiones gubernamentales que generaron descontento en amplios sectores de la población y con un elemento visual compartido: una rueda de prensa del presidente en un momento clave de la crisis, secundado por miembros de las Fuerzas Armadas. Esta configuración visual se asume en este trabajo como una expresión de la dinámica de militarización, así como un rasgo singular de esta. Las imágenes analizadas son las que se difundieron desde las redes sociales de las respectivas presidencias, junto con el discurso que pronunciaron ambos mandatarios.

\section{(a) El caso ecuatoriano: La gestión de Lenin Moreno}

En el caso ecuatoriano, el elemento que activó la movilización popular durante 12 días fue el decreto presidencial 883 que aprobó Lenin Moreno el 1 de octubre de 2019, con el que se eliminaban los subsidios a los combustibles. Dicha decisión se adoptaba, a su vez, como contrapartida a las reformas estructurales que exigía el FMI y otros organismos multilaterales por más de 10200 millones que se concedieron para sanear las cuentas fiscales. Un acuerdo que no fue objeto de diálogo ni debatido en el poder legislativo (Ramírez, 2019).

Con la medida de ajuste que suponía el decreto 883 , se producía un aumento de más del $123 \%$ en el diésel y la gasolina, y se expandían sus efectos más allá del sector del transporte pesado y pasajeros, al aumentar el precio de los pasajes y del transporte de todo tipo de mercancías, donde los sectores más empobrecidos son los más perjudicados. Ante el malestar que generó la decisión, distintas protestas empezaron a extenderse alrededor del país, encabezadas por el sector transportista que paralizó el país el 3 y 4 de octubre de ese mismo año, y amplificadas más tarde por el movimiento indígena articulado en torno a la Confederación de Nacionalidades Indígenas del Ecuador (CONAIE). En esa coyuntura de crisis, se convocó un paro nacional para el 9 de octubre de 2019 y una marcha hacia la capital ecuatoriana, respondida por parte del presidente Moreno con la rueda de prensa en la que anuncia el estado de excepción y el traslado provisional del Ejecutivo desde la capital hacia Guayaquil. 
La rueda de prensa del presidente Lenin Moreno se produce el 7 de octubre de 2019 (CNN, 2019). Dicha alocución la realiza sentado y acompañado de seis personas (ver Figura 1), dos sentadas junto a él y cuatro a sus espaldas. Sentados junto a él se encuentra al vicepresidente, Otto Sonnenholner, a la derecha del mandatario; y el ministro de Defensa, Oswaldo Jarrín, a su izquierda. En cuanto a los cuatro altos mandos de la cúpula militar ecuatoriana que figuran a sus espaldas, se trata, en orden de derecha a izquierda, del contralmirante Darwin Jarrín Cisneros, alto mando de la Fuerza Naval del Ecuador; del general de División Javier Pérez, comandante del Ejército; del general de División Roque Moreira Cedeño, jefe del Comando Conjunto de las Fuerzas Armadas y del teniente general Mauricio Campuzano, alto mando de la Fuerza Aérea del Ecuador (FAE).

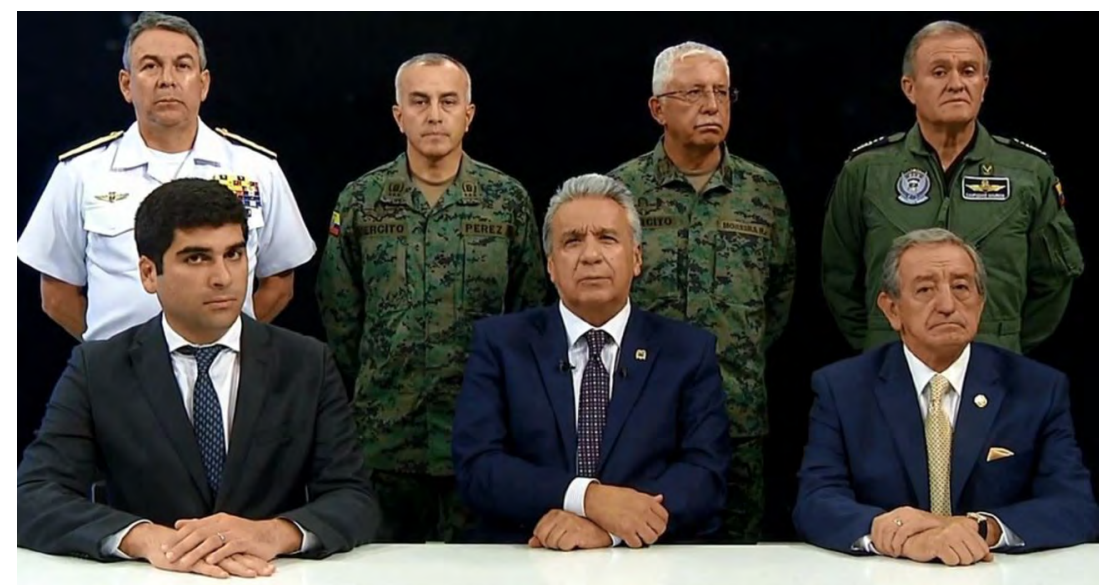

Figura 1

Imagen de la rueda de prensa de Lenin Moreno (7 de octubre de 2019)

Fuente: Presidencia de Ecuador (2019).

Se observa, así, cómo la rueda de prensa se proyecta con siete hombres, la mayoría uniformados - cuatro respecto a tres-, y con cinco de los allí presentes con origen castrense, incluido el ministro de Defensa - General de División, en servicio pasivo, con 35 años de carrera militar, jefe del Comando Conjunto de las FF.AA. entre 2002 y 2003 - , tras 12 años de ministros civiles en esa cartera durante los mandatos de Rafael Correa.

La composición de la rueda de prensa evoca un enmarcado netamente masculinizado, y con una simbología acaparada por el respaldo de los militares de más alto rango al mandatario civil. Como las omisiones también hablan por sí 
mismas, el hecho de que Moreno esté acompañado de este elenco de cargos, y en ausencia del responsable de la cartera de energía, finanzas o aspectos sociales, deja patente que la composición de la propia rueda de prensa es de naturaleza securitaria, e incluso, se podría enfatizar que militarizada. Esto último, ya que se echa en falta la presencia de la ministra de Gobierno, María Paula Romo, responsable de la cartera ministerial que tiene a cargo la Policía Nacional.

En la alocución de Lenin Moreno, durante la rueda de prensa, este empieza negando que se enfrente a una movilización social y señala que existe una "intención política para desestabilizar", por parte de individuos externos, entre los cuales cita al expresidente Rafael Correa y a Venezuela. Incluso se hace alusión a un intento de golpe de Estado "financiado con los recursos que robaron" y a la instrumentalización de algunos movimientos. Llama la atención que se llegue a plantear que se evitará el derramamiento de sangre, mientras esta alocución se realiza con los altos mandos de las Fuerzas Armadas, y se adopta una postura maniquea que agrupa el campo político entre los partidarios, según este, del "orden, la paz y la democracia"; frente a los "ociosos, ladrones y contrabandistas". Agrega que, en relación con la medida que provoca el estallido social recordemos, la supresión de los subsidios a los hidrocarburos-, "no voy a dar marcha atrás porque lo correcto no tiene matices" (CNN, 2019).

Además, como este mismo apunta, "agradece y destaca el compromiso de las Fuerzas Armadas y de la Policía Nacional" que "con absoluta lealtad han defendido, en el marco del Estado de Derecho y las libertades civiles, la democracia y las instituciones, con su apoyo y trabajo permanente". A lo que añade, casi sin pausa, "siempre desde el Gobierno vamos a defender los derechos y la tranquilidad ciudadana". Precisamente, el Estado de excepción que se aprueba, junto con el traslado del Ejecutivo a Guayaquil, es el que habilita al presidente a disponer de las Fuerzas Armadas para labores internas, en línea con el artículo 165 de la Constitución ecuatoriana aprobada en 2008. De lo contrario, primaría el artículo 158 de la carta magna que limita como función privativa del Estado y responsabilidad de la Policía Nacional la protección interna y el mantenimiento del orden público (Constitución de Ecuador, 2008). Es decir, la securitización de la crisis política habilita a Moreno a hacer un uso de las Fuerzas Armadas que, de lo contrario, no podría ejercer.

Ante protestas similares, cuando el mandatario se quedó en Quito, terminó cayendo por la fuerza de la movilización. En este caso, se opta por trasladar el ejecutivo completo a la segunda ciudad del país, Guayaquil, lo que no deja de reflejar el temor a la movilización que se había convocado y la debilidad del poder ejecutivo en ese momento. A su vez, tampoco conviene perder de vista que, 14 días después de la aprobación del decreto 883, con unas protestas que 
dejaron siete personas muertas, 1340 heridas y 1152 detenidas; tras alcanzar un acuerdo político con la CONAIE, el presidente ecuatoriano derogó la medida (Infobae, 2019); o lo que es lo mismo, un acuerdo político tras una negociación entre las partes, resolvió el conflicto político.

\section{b) El caso chileno: La gestión de Sebastián Piñera}

No transcurrieron dos semanas desde los acontecimientos que se registraron en Ecuador para que se repitiera una fotografía similar en Chile, y como reacción, igualmente, a una medida gubernamental que generó malestar en amplios sectores de la sociedad. En este caso, la movilización se desencadenó al aprobarse un aumento de los precios del transporte público que entraba en vigor el 6 de octubre de 2019. Dicha medida se tomaba por recomendación de un panel experto sobre transporte público y se tradujo en una subida del precio del pasaje del suburbano en 30 pesos, que llegó a un máximo de 830 pesos. Como muestra de desaprobación ante la medida, un grupo de estudiantes de secundaria convocó, como protesta, una evasión masiva en el metro de Santiago, el lunes 7 de octubre de 2019, un día después de la entrada en vigor de la medida.

La respuesta gubernamental, con despliegue de policías y militares, alimentó la movilización e inició una escalada que trascendía la reclamación del metro y fue extendiéndose a otras ciudades más allá de la capital (Santiago de Chile). Conforme los repertorios de la protesta también se ampliaron a caceroladas y se incrementaba la aceptación por parte de amplios sectores de la ciudadanía chilena, se registraban en paralelo cortes en el transporte público y desperfectos que empezaron a ser el motivo esgrimido para intensificar la respuesta securitaria por parte del Gobierno de Piñera. Al empleo inicial de los Carabineros en la represión de las protestas se sumó la declaración del estado de alarma y toque de queda a partir del 19 de octubre del 2019. Estas últimas medidas, empleadas con frecuencia durante la dictadura de Pinochet, suponían algo inédito por razones de desorden civil en la democracia chilena. El general de División, Javier Iturriaga del Campo, jefe de Defensa Nacional, fue designado por Piñera a cargo de las zonas en estado de emergencia.

Ese mismo sábado 19 de octubre, el presidente chileno, saliendo del enmarcado en clave de seguridad que había predominado en la gestión gubernamental, anuncia una propuesta para suspender el alza de precio del transporte público, al mismo tiempo que convoca, al día siguiente, a representantes de los poderes del Estado - Senado, Cámara de Diputados y Corte Suprema - de cara a buscar soluciones a largo plazo. El domingo 20 de octubre, al ver que la respuesta sigue sin calmar las protestas, y que estas continúan amplificándose con 
saqueos y los primeros fallecidos, se produce la rueda de prensa del presidente rodeado de militares.

Respecto a la rueda de prensa propiamente, como se observa en la Figura 2, se produce tras circularse unas imágenes de Piñera en una sala de crisis de la Guarnición Militar de Santiago, acompañado de un amplio elenco de personal castrense. Más de una quincena de ellos uniformados y situados a las espaldas del mandatario. La imagen traslada así un mensaje visual doble: por un lado, tener al presidente Piñera al frente de la mayor crisis que experimenta el país desde la llegada de la democracia; y por otro, contar con el apoyo, conocimiento y medios de las Fuerzas Armadas chilenas a la hora de responder a ella.

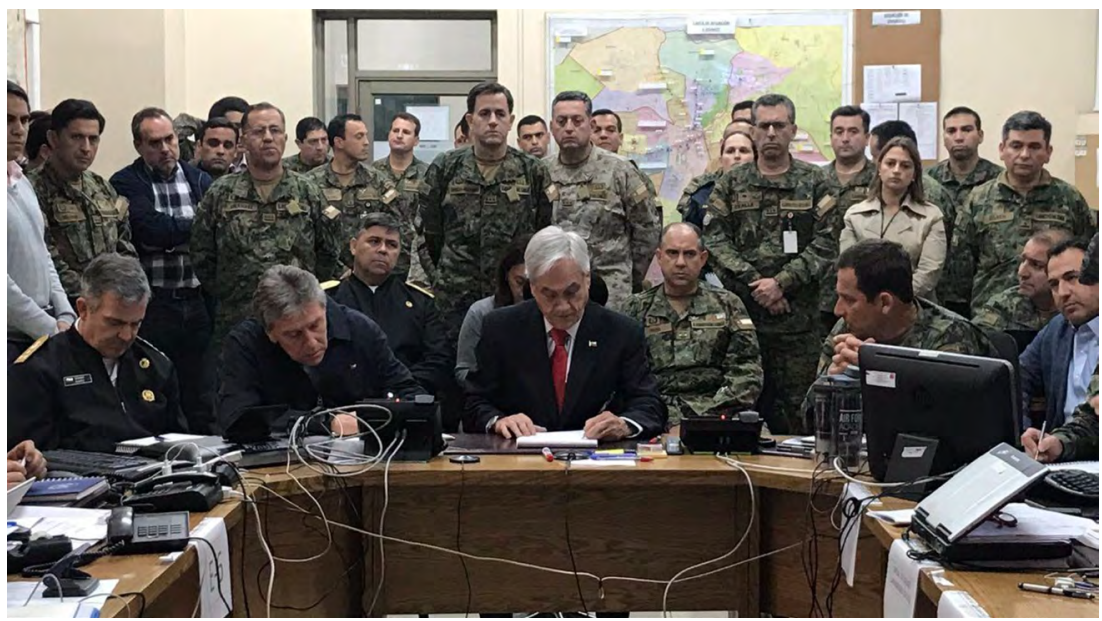

Figura 2

Imagen de la rueda de prensa de Sebastián Piñera (20 de octubre de 2019)

Fuente: Presidencia de Chile (2019).

En esa misma imagen, Piñera aparece sentado presidiendo la mesa, con el ministro de Defensa de Chile, Alberto Espina, a la izquierda de la imagen, y con el general Iturriaga a la derecha. Las declaraciones que realiza el presidente chileno, en cambio, las realiza de pie, acompañado por los mismos cargos que estaban sentados junto a él en la sala de crisis, si bien se enfoca sobre todo a Piñera. En todo caso, aquí se constata que la crisis se enmarca desde un prisma securitario y militarizado, al no encontrar ningún responsable de carteras ministeriales distintas a las de Defensa, y que uno de los dos que acompañan a Piñera sea un alto mando militar. 
Durante la intervención que sigue a la instantánea, tiene lugar su polémica afirmación en los términos siguientes:

Estamos en guerra contra un enemigo poderoso e implacable que no respeta a nada ni a nadie, y que está dispuesto a usar la violencia sin ningún límite incluso cuando significa la pérdida de vidas humanas, ... con el único propósito de producir el mayor daño posible, a todos los chilenos. (T13, 2019)

Repite esta idea, y añade que "se está en guerra contra todos los chilenos de buena voluntad". A su vez subraya que "no es tiempo de ambigüedades", "no es tiempo de dudas", y que es preciso unirse frente a aquellos que "representan la maldad". La narrativa bélica se acompaña, así, de todos los elementos de maniqueísmo que articulan un campo entre el bien y el mal, con los partidarios de vivir en libertad y vivir en paz, por un lado; y los que aspiran a destruir, por el otro $(\mathrm{T} 13,2019)$.

A su vez, frente a este "enemigo", las declaraciones se acompañan de las medidas adoptadas — estado de emergencia y activación de la ley de seguridad del Estado-, así como del despliegue de más de 9500 hombres para "restaurar los derechos y libertades". Ese momento, es aprovechado por el presidente chileno para expresar el profundo agradecimiento y reconocimiento a la labor que cumplen las Fuerzas Armadas y las fuerzas del orden. Se interpela al general Iturriaga, además, para señalar que cuenta con el "total apoyo y respaldo" (T13, 2019).

Se ampara el mandatario en la Constitución chilena para afirmar que la labor del Gobierno es proteger y justifica las medidas, porque se responde a la actuación de "criminales", "violentistas" y "delincuentes", se apoya en la logística que, según el propio Piñera, disponen aquellos que emplean la fuerza para imponer sus ideas $(\mathrm{T} 13,2019)$.

Tras esas declaraciones y dentro de un ciclo de movilización que supera el objetivo de este trabajo, merece destacar que las protestas volvieron a incrementarse con manifestaciones masivas y una nueva escalada de violencia, se extienden hasta el 12 de noviembre del 2019, e incluyen la suspensión de varios eventos internacionales que albergaba Chile en esas semanas, como el encuentro del Foro de Cooperación Económica Asia Pacífico y la Cumbre Mundial del Clima (COP25). Ese día, el presidente chileno se dirigió nuevamente, en cadena nacional de televisión, con una cuota de pantalla histórica y anunció una serie de tres "acuerdos nacionales" para responder a las protestas: el primero: (i) "por la paz y contra la violencia", incluía el llamado a uniformados retirados para que se integraran a las fuerzas de orden; (ii) "por la justicia", en que reiteraba el nuevo acuerdo social que se había planteado semanas atrás, y (iii) “por una nueva Constitución, dentro 
del marco de nuestra institucionalidad democrática". Para esto último se iba a celebrar un plebiscito el 26 de abril de 2020 que fue suspendido por la pandemia de la COVID-19 y se celebró, finalmente, el 25 de octubre 2020, el cual aprobó la apertura de un proceso constituyente con un 78,28\% de apoyo.

En los casos expuestos, y ante las mayores crisis políticas que han atravesado Ecuador y Chile en los últimos años, se constata una politización de los militares, la cual sobrepasa el rol tradicional -de defensa ante agresiones externas- que le corresponde y se apela a su intervención en contextos excepcionales. En ambos casos se constata que las imágenes adquieren una importancia en sí mismas y transmiten un doble mensaje a quien las observa: por un lado, el subtexto más evidente que se recoge cuando la rueda de prensa es de un político junto con los militares es que "los militares están conmigo". Ante los eventos críticos expuestos, tener a los militares a las espaldas del político que está protagonizando una rueda de prensa, transmite un mensaje a quien está viendo la imagen que la soberanía reside en quien tiene al factor castrense de su lado. Poco importa que el mandatario en cuestión tenga movilizaciones en su contra o esté dispuesto a abandonar la capital de su país, como en el caso de Lenin Moreno, siempre y cuando tenga a el apoyo de las Fuerzas Armadas.

Aquí, nuevamente, se comprueba las hipótesis del "nuevo militarismo" o la dinámica de remilitarización en la región, al ser los propios mandatarios los que recurren a las Fuerzas Armadas para la gestión de las crisis políticas y, por lo tanto, son los responsables civiles quienes militarizan las crisis. Se constata, asimismo, como uno de los efectos más claros de la dinámica de remilitarización y se plasma en la gestión de estas crisis: la polarización del discurso, o lo que es lo mismo, el recurso al maniqueísmo para dividir el campo político en dos; se borra, así, cualquier margen de postura más matizada o compleja. En ambos casos se criminaliza a quienes protestan, y se apela al cierre de filas entre quienes se presentan como los defensores de la "democracia", el "orden" y la "paz" frente a los "violentos" y "delincuentes".

Otro de los efectos que se aprecia en este análisis de las crisis en Ecuador y Chile es la vulneración de derechos humanos puesta en evidencia por distintos organismos especializados durante el transcurso de estas crisis. En cada una de ellas, se registran cifras preocupantes de muertes, heridos y detenidos. En el caso de Ecuador, 7 personas fallecidas, 1340 heridas y 1152 detenidas, mientras en Chile se contabilizan 22 personas fallecidas, 2200 heridas y 6 300 detenidas. En el caso chileno que se ha extendido durante más semanas, Amnistía Internacional denuncia, además, crímenes de derecho internacional, graves violaciones de derechos humanos con intencionalidad y generalidad. Concretamente, se aprecia (i) uso letal de la fuerza, (ii) tortura y malos tratos, 
(iiii) lesiones graves y uso de armas potencialmente letales, y (iv) limitación del trabajo de personas defensoras de derechos humanos (Amnistía Internacional, 2019). Con ello, se observa cómo los discursos militarizados se acompañaron de unas prácticas que conviene tener presentes e insertar en el análisis.

Por otro lado, la imagen tiene otro subtexto para quien la observa: quien ponga en duda la legitimidad del político que cuenta con el apoyo de las Fuerzas Armadas tendrá que asumir que este puede recurrir a estos cuerpos para garantizar la "estabilidad y el orden interno", aunque estos cuerpos estén formados para reducir enemigos externos y combatir en entornos bélicos. O lo que es lo mismo, quien discuta la legitimidad de quien cuenta con el apoyo de las Fuerzas Armadas se expone a su represión por parte de estos cuerpos. Esta militarización de carácter visual, tal y como se ha puesto en evidencia en el trabajo sobre securitización de Vuori (2008), implicaría, así, un efecto de disuasión en aquel que difiera con el mandatario y quiera expresarlo públicamente.

Se observa, de esta manera, cómo varias democracias latinoamericanas han registrado momentos de crisis en las que el factor militar ha ganado protagonismo, erosionando la legitimidad racional y democrática que le corresponde a la ciudadanía a través de las elecciones y el ejercicio del derecho de manifestación. Se corrobora y refuerza, así, uno de los roles de las Fuerzas Armadas que afloran con la dinámica de remilitarización expuesta: el uso del elemento castrense como reaseguro frente a crisis sociopolíticas por parte del mandatario de turno, con unos efectos visuales que interpelan al espectador con un doble mensaje: disuasión ante su disenso y proyección de soberanía para el actor político civil que cuente con el respaldo de las Fuerzas Armadas.

\section{Reflexiones finales}

Dos imágenes se suceden en Ecuador y Chile, con pocos días de margen entre una y otra, en la que sobresalen los mismos protagonistas en el contra fondo - las Fuerzas Armadas-, y en primer plano un mandatario cuya gestión está en entredicho tras una medida impopular que se ve obligado a intervenir a través de los medios de comunicación. Como se ha apuntado, son instantáneas que empiezan a repetirse con regularidad en la región y sobre las que conviene ahondar, dado que subyace en todas ellas una dinámica de remilitarización más intensa en los últimos tiempos en América Latina. 
Como una contribución a la emergente agenda sobre política visual en relaciones internacionales, y desde la metodología pluralista correspondiente, este trabajo ha analizado dos situaciones de crisis en América Latina, enmarcadas en una oleada de protestas que se produjeron durante el último trimestre de 2019. A partir de los casos de Lenin Moreno, en Ecuador, y Sebastián Piñera, en Chile, se ha contextualizado qué explica ese malestar y en qué circunstancias se produce una intervención con una configuración escénica que no es fruto de la casualidad. En ambos casos, se observa, por un lado, la voluntad de proyectar con un lenguaje no verbal el apoyo de las Fuerzas Armadas en un momento de cuestionamiento del liderazgo y la gestión del mandatario en cuestión; y por otro, la pretensión de disuadir a quienes secunden las protestas que originan las alocuciones. En una respuesta gubernamental securitizada y con un discurso que apela a enemigos externos jamás probados, quien no está del lado del mandatario se expone a recibir la respuesta de quienes le apoyan, como en este caso, de las Fuerzas Armadas.

Por supuesto, las imágenes no son solo un ejercicio estético, y se acompañan de unas medidas excepcionales que permiten justificar el endurecimiento de la respuesta gubernamental a las protestas. Así, además del respaldo y la disuasión de las Fuerzas Armadas, las medidas se acompañan desde un prisma democrático y de derechos humanos, de una vulneración del deber de neutralidad de un instrumento del Estado -no del Gobierno de turno-, y una serie de consecuencias por los afectados debido a estas gestiones. Así, del mismo modo que aquí se ha atendido tanto al contexto, como la construcción de la imagen y el contenido, sería oportuno no perder de vista el impacto o cómo se han recibido estas estampas.

A su vez, y si bien los desenlaces políticos en ambos casos son distintos, la matriz común durante la gestión puede encontrarse en estas crisis y otras que ha registrado la región. Por ello, sería oportuno dar continuidad a la línea de trabajo abierta, ampliando los casos seleccionados a otras coyunturas de crisis en la región, como la crisis en Guatemala tras la expulsión de la Comisión Internacional contra la Impunidad en Guatemala (CICIG) por parte de Jimmy Morales, las protestas que se registraron en Colombia en esa misma oleada y la reacción de Iván Duque, o el caso de Bolivia tras las elecciones de 2019 y la toma de posesión de Jeanine Áñez. El reto epistemológico hace que la problemática no se aborde con facilitad, aunque el impacto democrático y desde un enfoque de derechos bien merece afrontarlo. 


\section{Referencias}

Adler-Nissen, R., Andersen, K. E., y Hansen, L. (2020). Images, emotion, and international politics: the death of Alan Kurdi. Review of International Studies, 46(1), 75-95.

Amnistía Internacional. (2019). Chile: Política deliberada para dañar a manifestantes apunta a responsabilidad de mando, 21 de noviembre de 2019. https://www.amnesty.org/es/latest/news/2019/11/ chile-responsable-politica-deliberada-para-danar-manifestantes/

Bleiker, R. (2015). Pluralist methods for visual global politics. Millenium: Journal of International Studies, 43(3), 872-890.

Bleiker, R. (2014). Visual Assemblages: From Causality to Conditions of Possibility. En M. Acuto y S. Curtis (Eds.), Reassembling International Theory. Ed. Palgrave, Hampshire.

Bleiker, R. (2018). Visual security: patterns and prospects. J. A. Vuori y R. Saugmann (Eds.), Visual security studies: sights and spectacles of insecurity and war (pp.189-200). Ed. Taylor \& Francis.

CNN. (2019). Lenín Moreno traslada sede del Gobierno de Ecuador a Guayaquil, video cargado el 8 de octubre de 2019. https://www.youtube.com/ watch?v=7duflXNIH_g

Constitución de Ecuador. (2008). Constitución de la República del Ecuador. Publicada en el Registro Oficial, n. ${ }^{\circ}$ 449, 20 de octubre de 2008. https://www. asambleanacional.gob.ec/sites/default/files/documents/old/constitucion_de bolsillo.pdf

Cooper-Cunningham, D. (2020). Visual Methods and International Security Studies. E-International Relations, junio de 2020. https://www.e-ir.info/2020/06/12/ visual-methods-and-international-security-studies/

Deleuze, G. \& Guattari, F. (1987). A Thousand Plateaus Capitalism and Schizophrenia. University of Minnesota Press.

Diamint, R. (2001). Democracia y seguridad en América Latina. Grupo Editor Latinoamericano-UTDT.

Diamint, R. (2015). A new militarism in Latin America. Journal of Democracy, 26(4), 155-168.

España, S. (2019). El Gobierno de Ecuador se traslada a Guayaquil ante la escalada de la crisis. El País, 9 de octubre de 2019 https://elpais.com/internacional/2019/10/08/america/1570502226_979384.html 
Hansen, L. (2011). The politics of securitization and the Muhammad cartoon crisis: A post-structuralist perspective. Security Dialogue, 42(4-5), 357-369.

Hansen, L. (2014). How images make world politics: International icons and the case of Abu Grahib. Review of International Studies, BISA, 1-26.

Hansen, L. (2018). Security. En R. Bleiker (Ed.), Visual global politics (pp. 209214). Routledge.

Heck, A. y Schlag, G. (2013). Securitizing images: The female body and the war in Afghanistan. European Journal of International Relations, 19(4), 891-913.

Hens, M. y Sanahuja, J. A. (1995). Seguridad, conflictos y reconversión militar en América Latina. Nueva Sociedad, 138 (julio-agosto), 48-69.

Martínez, P. A. y Rubio, P. (2017). América Latina actual. Del populismo al giro de izquierdas. La Catarata.

Mitchell, W.T.J. (1994). Picture Theory. Essays on Verbal and Visual Representation. The University of Chicago Press.

Moore, C., y Farrands, C. (2013). Visual analysis. Critical Approaches to Security: An Introduction to Theories and Methods (221-235). Routledge.

Presidencia de Chile. (2019). Prensa Presidencia de Chile, cuenta de Twitter de la Presidencia de Chile (@presidencia_cl), 20 de octubre de 2019. https://twitter.com/presidencia_cl/status/1186083645616017408

Presidencia de Ecuador. (2019). Presidencia ECU, cuenta de Twitter de la Presidencia de Ecuador (@Presidencia_Ec),7 de octubre de 2019.

Ramírez, F. (2019). Las masas en octubre. Ecuador y las colisiones de clase. Nueva Sociedad, 284 (noviembre-diciembre).

Rodríguez, E. (2020). La movilización social sacude América Latina. Política Exterior, 193, enero-febrero, Madrid.

Rose, G. (2016). Visual methodologies: An introduction to researching with visual materials (4. ${ }^{\text {ta }}$ ed.). Londres.

Sanahuja, J. A. (2018). Crisis de globalizacion, crisis de hegemonía: Un escenario de cambio estructural para América Latina y el Caribe. En A. SERBIN (Ed.), América Latina y el Caribe frente a un nuevo orden mundial: Poder, globalización y respuestas regionales. Icaria.

Sanahuja, J. A. (2019). América Latina: Malestar democrático y retos de la crisis de la globalización. Panorama Estratégico. Instituto Español de Estudios Estratégicos.

Sanahuja, J. A. y Verdes-Montenegro, F. J. (2014). Seguridad y defensa en Sudamérica: Regionalismo, cooperación y autonomía en el marco de Unasur. 
Anuario de la Integración de CRIES 2013-2014. Coordinadora Regional de Investigaciones Económicas y Sociales.

Scharpf, A. (2020). Dangerous Alliances: Populists and the Military. GIGA Focus, 1. https://assets.ctfassets.net/jlhgjubhhjuo/5oELa8KiS2d1yn42LngEpk/ fd35b24dee1fec97e5e454f47a3356af/web-LA-2020-01-en.pdf

Schlag, G. (2019). Thinking and Writing Visual Global Politics - a Review of R. Bleiker's Visual Global Politics (2018), Abingdon and New York: Routledge. International Journal of Politics, Culture and Society, 32, 105-114.

T13. (2019). Presidente Piñera: «Estamos en guerra contra un enemigo poderoso». Tele 13, Santiago, cargado el 21 de octubre de 2019. https://www.youtube. com/watch? $\mathrm{v}=\mathrm{jlxxnm} 7 \mathrm{dGUA}$

Verdes-Montenegro, F. J. (2015). Securitización: agendas de investigación abiertas para el estudio de la seguridad. Relaciones Internacionales, 29 (junio-septiembre), GERI-UAM, Madrid.

Verdes-Montenegro, F. J. (2019). La (re)militarización de la política latinoamericana: origen y efectos para las democracias de la región. En Documentos de Trabajo de la Fundación Carolina, n. ${ }^{\circ}$ 14. Fundación Carolina.

Vuori, J. A. (2008). Illocutionary logic and strands of securitization: Applying the theory of securitization to the study of non-democratic political orders. European journal of international relations, 14(1), 65-99.

Vuori, J. A. (2010). A timely prophet? The doomsday clock as a visualization of securitization moves with a global referent object. Security Dialogue, 41(3), 255-277.

Vuori, J. A. (2013). Pictoral texts. En M. B. SALTER, \& C. E. MUTLU (Eds.), Research Methods in Critical Security Studies: An Introduction (pp. 199-202). Routledge.

Vuori A. y Andersen R. S. (2018). Introduction. En J. Vuori, \& R. Saugmann (Eds.), Visual security studies: sights and spectacles of insecurity and war Routledge.

Williams, M. C. (2018). International Relations in the Age of the Image. International Studies Quarterly, 62(4), 880-891. 